\title{
Loop Electrosurgical Excision Procedure in Cervical Intraepithelial Neoplasia
}

\author{
Maharjan R, ${ }^{1}$ Thapa BK, ${ }^{1}$ Chitrakar NS, ${ }^{1}$ Pariyar J, ${ }^{1}$ Shrestha I, ${ }^{1}$ Joshi AP, ${ }^{1}$ Maharjan P, ${ }^{1}$ Neupane S, \\ Koirala S. $^{2}$ \\ ${ }^{1}$ Department of Obstetrics and Gynecology, ${ }^{2}$ Department of Pathology, Nepal Civil Service Hospital
}

Received: January 22, 2016 ; Accepted: March 22, 2016

\begin{abstract}
Aims: To evaluate the treatment outcome and acceptance of LEEP in precancerous cervical lesions.
Methods: CIN is the pre-malignant cervical lesion that can be treated early and slow to progress to invasive disease. Among various treatment modalities for CIN, LEEP has the advantage of treatment with tissue diagnosis.

Results: Highest percentage of CIN, 32.14\% (9) was seen among 30-39 years age with 16 (57.14\%) of parity three and more. 17 (60.71\%) presented clinic with symptoms (lower abdominal, backpain, pervaginal discharge) while $11(39.28 \%)$ were diagnosed from routine Pap test. Histopathology revealed four (14.28\%) CIN 1, eight (28.57\%) CIN2, 11(39.28\%) CIN 3, two adenocarcinoma in situ, one of invasive squamous cell carcinoma, chronic cervicitis and atrophic change with no dysplasia. Margins were negative (satisfactory) in 20 (71.42\%) and positive in eight (28.57\%) with endocervical involvement in two that required second LEEP while one underwent radical hysterectomy for final diagnosis of invasive squamous cell carcinoma.
\end{abstract}

Conclusions: Hysterectomy is a radical procedure for preinvasive cervical lesions that can be treated with simple procedure like LEEP that saves time and financial resources.

Keywords: CIN; LEEP

\section{INTRODUCTION}

Cervical cancer is the commonest cancer among Nepalese women. among estimated 270,000 deaths from cervical cancer every year worldwide, $85 \%$ occur in developing countries like Nepal. More than 3,500 new cases of invasive cervical cancer are diagnosed in Nepal each year which accounts for $21 \%$ of all cancers in women. ${ }^{1,2}$ Cervical intraepithelial neoplasia (CIN) is the most common pre-malignant lesion that is slow to progress to invasive disease. Spectrum of atypical squamous changes occurs in transformation zone of cervix from cellular atypia to various grades of dysplasia described as CIN 1, 2 or 3 , before progressing to invasive disease. There are various modalities of treatment for $\mathrm{CIN}$ ranging from conservative management, ablative as cryotherapy, excisional procedure like LEEP to hysterectomy.

LEEP enables simultaneous treatment of lesions and provides tissue for histologic diagnosis, thereby reducing possibilities of overlooking invasive cancer

\section{CORRESPONDENCE}

Dr Rima Maharjan

Department of Obstetrics and Gynecology

Nepal Civil Service Hospital

Email:m_reema@hotmail.com

Phone: +977-9841346195 or incomplete eradication of precancerous cells. LEEP is shown to be effective in treating 90 to 95 percent of high-grade dysplasia. ${ }^{3}$ Number of large series treating thousands of patients have documented excellent treatment outcomes ranging from $91 \%$ to 98 $\%{ }^{4}$

Cervical cancer prevention programs must offer appropriate and effective treatment options for precancerous cervical lesions. However, due to unavailability of the facilities for conservative surgeries, women are often treated with hysterectomy which is an invasive and costly procedure.

\section{METHODS}

A descriptive study was performed in Gynecology Department of Civil Service Hospital, Nepal from August 2014 to December 2015. A total of 28 cases that had undergone LEEP for pre-invasive cervical lesions, were analyzed. The lesions were detected in Pap smear followed by cervical biopsy with or without colposcopy guidance with histopathological confirmation and grading was done in Cervical Intraepithelial Neoplasia (Richart) system.

Clinical history recorded the age at marriage, the first contact and child birth, parity, occupation, smoking habit and use of OCP. Medical conditions as hypertension, diabetes, bleeding disorder, allergic 
reaction, pregnancy, PID and invasive cancers were excluded prior to the procedure.

Patients were well informed about the procedure, all possible and expected post procedure symptoms and an informed written consent was taken. Patients were also counseled regarding the need of regular follow up post procedure and additional treatment depending upon the final histopathological report and the margin status.

LEEP was performed as a day care procedure under intra venous anesthesia. Single or multiple passes or two layer excisions were carried out depending on the extent of lesion. Patient was sent home six hours after surgery having counseled on home care, abstinence from sexual intercourse for next four weeks, signs and symptoms on which they should report. The first follow up was done after one week to review the histopathology reports and assess for any signs of infection or bleeding. Patents were then inquired regarding any problems faced and their perception about the procedure and were asked to follow up according to NCCN guidelines 2012.5

\section{RESULTS}

Total 28 cases underwent LEEP. The age of the patients ranged from 30 to 64 years with a mean age of 45.96 years. The highest percentage of CIN, 32 $(n=9)$ was observed among 30-39 years. Average age of marriage and age at first child birth were 19.71 and 22.57 years respectively (Table 1 ). All of the women were married, three $(10.9 \%)$ had parity one, nine (32.1\%) had parity two and $16(57.1 \%)$ had parity three or more.

Table 1: Demographic profile of women

\begin{tabular}{|ll|}
\hline Demographic Characteristics & Number \\
\hline Age in years & \\
$30-39$ & $9(32 \%)$ \\
$40-49$ & $8(28.5 \%)$ \\
$50-59$ & $7(25 \%)$ \\
$\geq 60$ & $4(14.5 \%)$ \\
Parity & \\
0 & 0 \\
1 & $3(10.9 \%)$ \\
2 & $9(32 \%)$ \\
$\geq 3$ & $16(57.1 \%)$ \\
Mean age at marriage 19.71 years & \\
& \\
Mean age at first child birth 22.57 & \\
years & \\
\hline
\end{tabular}

$17(60.71 \%)$ of women with CIN presented to outpatient clinic with symptoms while 11 (39.29\%) were apparently healthy women and diagnosed on routine Pap test. Per vaginal discharge with or without low back pain was the commonest complaint, seen in $16(57.1 \%)$ women. Other presenting complaints included intermenstrual bleeding, post coital bleeding and pain abdomen. CIN 2 and 3 had mostly presented with heavy per vaginal discharge followed by lower abdominal pain and/or post coital bleeding (Table-2). The symptoms were reduced in $85-87 \%$ cases post LEEP.

Table 2: Comparison of Symptoms pre and post procedure

\begin{tabular}{|c|c|c|c|c|}
\hline \multirow[t]{2}{*}{ Symptoms } & \multirow{2}{*}{$\begin{array}{l}\text { Before } \\
\text { LEEP }\end{array}$} & \multicolumn{3}{|c|}{ After LEEP } \\
\hline & & Reduced & $\begin{array}{l}\text { Dis } \\
\text { appeared }\end{array}$ & Persistent \\
\hline None & $\begin{array}{l}11 \\
(39.29 \%)\end{array}$ & & & \\
\hline $\begin{array}{l}\text { Symptoms } \\
\text { PV } \\
\text { discharge }\end{array}$ & $\begin{array}{l}\mathbf{1 7} \\
(\mathbf{6 0 . 7 1 \% )} \\
16\end{array}$ & 6 & 3 & 1 \\
\hline $\begin{array}{l}\text { Lower } \\
\text { abdominal } \\
\text { pain }\end{array}$ & 5 & 0 & 2 & 3 \\
\hline $\begin{array}{l}\text { Post coital } \\
\text { bleeding }\end{array}$ & 2 & 0 & 2 & 0 \\
\hline $\begin{array}{l}\text { Intermenstrual } \\
\text { bleeding }\end{array}$ & 3 & 0 & 3 & 0 \\
\hline Back pain & 15 & 8 & 2 & 5 \\
\hline
\end{tabular}

There were two cases (7.14\%) of CIN 1, 11(39.29\%) of CIN 2 and 15 (53.57\%) cases of CIN 3 diagnosed pre-operatively by Pap test and verified by cervical biopsy. However, post LEEP final histopathology revealed four (14.28\%) of CIN 1, eight (28.57\%) CIN 2, 11(39.28\%) CIN 3, one case each of chronic cervicitis, a case of atrophic changes with no features of dysplasia, two cases of adenocarcinoma in situ and a case of invasive squamous cell carcinoma (Table 3).

Table 3: Histopathological diagnosis

\begin{tabular}{|llll|}
\hline Diagnosis & $\begin{array}{l}\text { Pre LEEP } \\
\text { Pap Smear }\end{array}$ & $\begin{array}{l}\text { Post LEEP } \\
\text { Cervical } \\
\text { biopsy }\end{array}$ \\
\hline CIN 1 & $2(7.4 \%)$ & & $4(14.28 \%)$ \\
CIN 2 & $11(39.29 \%)$ & 16 & $8(28.57 \%)$ \\
CIN 3 & $15(53.57 \%)$ & 12 & $11(39.29 \%)$ \\
$\begin{array}{l}\text { Adenocarcinoma } \\
\text { in Situ (AIS) }\end{array}$ & & & $2(7.4 \%)$ \\
$\begin{array}{l}\text { Cancer (Invasive } \\
\text { or microinvasive) } \\
\begin{array}{l}\text { Negative ( chronic } \\
\text { cervicitis) }\end{array}\end{array}$ & & & 1 \\
\hline
\end{tabular}

Margin status was negative (satisfactory) in 22 cases $(78.5 \%)$ and six cases $(21.5 \%)$ with endocervical 
involvement in two (Table 4). Second LEEP was done after eight weeks of primary LEEP, in patients with endocervical involvement and histopathology then revealed margins free of dysplasia. One of the CIN 3 cases had final histopathological diagnosis of invasive squamous cell carcinoma and underwent radical hysterectomy.

Table 4: Histopathological status of margins

\begin{tabular}{|llll|}
\hline Margin status & $\begin{array}{l}\text { right and left } \\
\text { lateral, upper } \\
\text { or lower }\end{array}$ & $\begin{array}{l}\text { Endocervical } \\
\text { involvement } \\
\text { (Deeper margin) }\end{array}$ \\
\hline Positive & $6(21.5 \%)$ & Present & $2(7 \%)$ \\
Negative & $22(78.5 \%)$ & Absent & $26(93 \%)$ \\
\hline
\end{tabular}

\section{DISCUSSION}

Invasive cervical cancer is preceded by a long phase of preinvasive stage, Cervical Intraepithelial Neoplasia (CIN) which is slow to progress and can be detected and easily treated. Three grades of CIN described are CIN 1 (mild dysplasia), CIN 2 (moderate dysplasia), and CIN 3 (severe dysplasia/carcinoma in situ) depending upon epithelial involvement. Most of the CIN 1 (57\%) and about 43\% of CIN 2 lesions regress spontaneously within one to two years. Only $11 \%$ of CIN 1 and $22 \%$ of CIN 2 progress to cervical carcinoma in situ while $1 \%$ of CIN 1, 5\% in CIN 2 and at least $12 \%$ in CIN 3 progress to invasive cancer. ${ }^{6}$ Thus, CIN should be detected by cervical screening and treated appropriately which we have in our cases.

$\mathrm{CIN}$ is more common among younger women as observed in our study (30-39 years) and in a study by Dietsch et al. ${ }^{7}$ where the peak age of CIN was 20-24 years while in another study by Pandey et al., 8 the mean age of CIN was $36.38 \pm 6.5$ years. In these young women LEEP has played an important role in treating the precancerous lesion with preservation of the important female organ.

Among various modalities available for pre cancerous lesions, LEEP has the advantage of low cost, high success rate, ease of use that can be done as office procedure and above of all it provides tissue for definitive diagnosis. This makes wide use of LEEP for both diagnostic and therapeutic purposes in patients with CIN 2, CIN 3 and CIS as done in our cases.

LEEP effectively treats CIN. Wright et al has reported cure rate of LEEP to be $94 \%$ with large electrode and $80 \%$ with small electrode ${ }^{9}$ while Rema et al stated the effectiveness of $93 \%$ in CIN 1, 85.5\% in CIN 2 and $72 \%$ in CIN $3 .{ }^{10}$ Margin status is used as a predictor for residual or recurrent disease, although several studies have reported that margin status does not adequately predict probability of residual disease. ${ }^{12} \mathrm{In}$ our study 22 (78.5\%) had margin negative; six cases $(21.5 \%)$ had focal peripheral margin positive which contradicts the study by Kim et al where resected margins were positive in $81.39 \% .{ }^{11}$ Among the margin positive cases, two underwent second LEEP after eight weeks of primary procedure while one (3.5\%) underwent radical hysterectomy for invasive carcinoma which is comparable to study performed by Eduardo et al (3.6\%). ${ }^{12}$ However, our result is comparable to the study by Petry in which resected margins were positive in $18 \% .{ }^{13}$ Two patients with cervical margins positive without endocervical involvement deferred from standard follow up or second LEEP due to anxiety and requested for simple hysterectomy. Remaining patients expressed their feeling of satisfaction regarding the procedure in their subsequent follow ups as in the study by Mayeaux EJ Jr of high acceptance of the procedure by the patients. ${ }^{14}$

\section{CONCLUSION}

Cervical Intraepithelial Neoplasia, preinvasive state of cervical cancer predominantly occurs in younger age. LEEP is an effectively, rational and simple procedure for the treatment of CIN and thus prevention of cervical cancer. LEEP would save time and, possibly financial resources of both patient and health care service as it could avoid unnecessary hysterectomy.

\section{REFERENCES}

1. WHO. Human papillomavirus (HPV) and cervical cancer. Fact sheet No 380.WHO. 2015.

2. Nour NM. Cervical cancer: A preventable death. Rev Obstet Gynecol. 2009;2: 240-4.

3. Dodson MK, Sharp HT. Uses and abuses of the loop electrosurgical excision procedure (LEEP). Clin Obstet Gynecol. 1999;42: 916-21.
4. Prendiville W, Cullimore J, Norman S. Large loop excision of the transformation zone (LLETZ). A new method of management for women with cervical intraepithelial neoplasia. Br J Obstet Gynaecol.1989;96: 1054-60.

5. Lowe NK. Cervical Cancer Screening Guidelines 2012. J Obstet Gynecol Neonatal Nurs. 2013;42: 1-2.

6. Williams JW. Preinvasive Lesions of the Lower Genital Tract. In: Hoffman BL, Schorge JO, Schaffer JI, Halvorson 
LM, Bradshaw KD, Cunningham FG, editors. Williams' Gynecology. Second ed. McGraw-Hill Professional. 2008; p. 738-54.

7. Dietsch E, Gibb H, Francis K. Abnormal pap test results and the rurality factor. Aust J Rural Health. 2003;11: 50-6.

8. Pandey K, Bhagoliwal A. Cancer cervix-need for mass surveillance programme specially in rural areas. J Obstet Gynecol India. 2005; 55: 436-9.

9. Wright TC Jr, Gagnon S, Richart RM, Ferenczy A. Treatment of cervical intraepithelial neoplasia using the loop electrosurgical excision procedure. Obstet Gynecol. 1992;79: 173-8.

10. Rema P, Suchetha S, Thara S, Fayette JM, Wesley R, Sankaranarayanan R. Effectiveness and safety of loop electrosurgical procedure in low resource setting. Int $\mathrm{J}$ Gynaecol Obstet. 2008;103: 105-10.
11. Kim HJ, Kim KR, Mok JE, Nam JH, Kim YT, Kim YM et al. Pathologic risk factors for predicting residual disease in subsequent hysterectomy following LEEP conization. Gynecol Oncol. 2007;105: 434-8.

12. Eduardo AM, Dinh TV, Hannigan EV, Yandell RB, Schnadig VJ. Outpatient loop electrosurgical excision procedure for cervical intraepithelial neoplasia. Can it replace cold knife conization? J Reprod Med. 1996;41: 729-32.

13. Petry KU, Glaubitz M, Maschek H, Bohmer G, Linge G, Kuhnle H. Electrosurgical loop excision of the transformation zone in treatment of cervix neoplasia. Geburtshilfe Frauenheilkd.1996;56: 513-6.

14. Mayeaux EJ Jr, Harper MB. Loop electrosurgical excision procedure. J Fam Pract. 1993Feb;36: 214-9. 